\title{
Reconstructing Vindonissa as a Living Document A Case-study of Digital Reconstruction for Output to Pre-rendered and Real-time Applications
}

\author{
JONAS CHRISTEN, ikonaut GmbH, Switzerland / Zurich University of the Arts, Switzerland
}

The legion camp "Vindonissa" in Switzerland is considered one of the most important Roman excavation sites north of the Alps. Research there has been conducted for over a century and reconstructive drawings have always been a way to showcase scientific progress. The earliest of these drawings date back to 1909. In 2015, the local archaeological service decided that a new series of illustrations should be produced. Topographical data, archaeological plans, as well as building profiles provided by experts were the basis for these illustrations.

Future uses of the same model could include animations or real-time applications for augmented and virtual reality. In order to avoid remodeling for these uses, the whole camp and its surrounding settlements had to be constructed as adaptive and flexible 3D models. The requirements on a model for still rendering are very different from those on real-time renderings in game engines. Also, the reasonable level of detail for images on eye level is very different from the level of detail for bird's-eye panorama. Therefore, the main challenge was to develop an efficient workflow for multiple output media and different points of view.

While some of the proposed methods proved to facilitate the process without adding time needed for modeling, there still remain a lot of open questions. A "living document" should allow all stakeholders (excavators, archaeologists, historians, and illustrators) to access and change information in all stages of the process. This still has to be considered a long-term goal and is a problem far from being solved.

Key words:

Computer-visualization, 3D reconstruction, 3D modeling, Virtual Reality, Roman legion camp

SDH Reference:

Jonas Christen 2017. Reconstructing Vindonissa as a Living Document - A Case-study of Digital

Reconstruction for Output to Pre-rendered and Real-time Applications. SDH, 1, 2, 396-408.

DOI : $10.14434 /$ sdh.v1i2.23280

\section{INTRODUCTION}

The company ikonaut $\mathrm{GmbH}$ works closely with experts in order to accurately communicate scientific content either to other experts or to a broader public. Its members are trained scientific illustrators, aware of the trade-offs and dangers that are implicated by a visual reduction in complexity of content or the depiction of details that have no adequate scientific justification. In the case of the new digital visualizations of the Roman legion camp of Vindonissa, the client (the

Author's address: Jonas Christen, Zurich University of the Arts, Department of Design, Pfingstweidstrasse 96 CH-8005 Zürich, Switzerland; Email: jonas.christen@zhdk.ch

Permission to make digital or hardcopies of part or all of this work is granted without fee according to the open access policy of SDH.

(C) 2017 SDH Open Access Journal

Studies in Digital Heritage, Vol. 1, No. 2, Publication date: December 2017 
archaeological service of the canton of Aargau in Switzerland) decided deliberately to move away from the graphic style of previous visualizations and asked for three more detailed, photorealistic images. The leader of the Vindonissa excavations, Dr. Jürgen Trumm, very closely oversaw the process of the reconstruction and was responsible for the scientific accuracy of the buildings and the environment depicted.

Early in the process, the client and the company decided that they would attach importance to the reusability of the emerging model. It should not only be usable for this specific use-case but adaptable for future known and unknown uses with manageable investment of time and money.

\section{EARLIER VISUALIZATIONS OF VINDONISSA}

To understand the need for easily adaptable models, a short overview of the camp's history and previous visualizations reconstructing it are desirable. Inscriptions and coins were discovered in the area as far back as the 14th century, but excavations only started toward the end of the 19th century [Trumm 2015]. The earliest reconstruction drawings of Vindonissa date to 1909 [Trumm 2016] but they are limited to individual buildings whose remains give a clear indication to their original use (e.g. the amphitheater). The first attempt at a partial reconstruction of the camp dates to 1939 and was done by W. Eichenberger (Fig. 1a). Thanks to grey areas around the reconstructed part it clearly separates the better-known parts from areas that had not been excavated at that time. In 1945, architect H. Herzig drew the first full reconstruction of the camp (Fig. 1b). While the general layout and placement of the structures hold up to today's scientific findings, various detailed buildings are now thought to have looked very different, an obvious example being the factory-like houses with chimneys. Around a decade later, a colorful illustration with legionnaires in the foreground was made. It supposedly was published in a school book in the 1950s although no references of the author or the publication could be found (Fig. 2a).

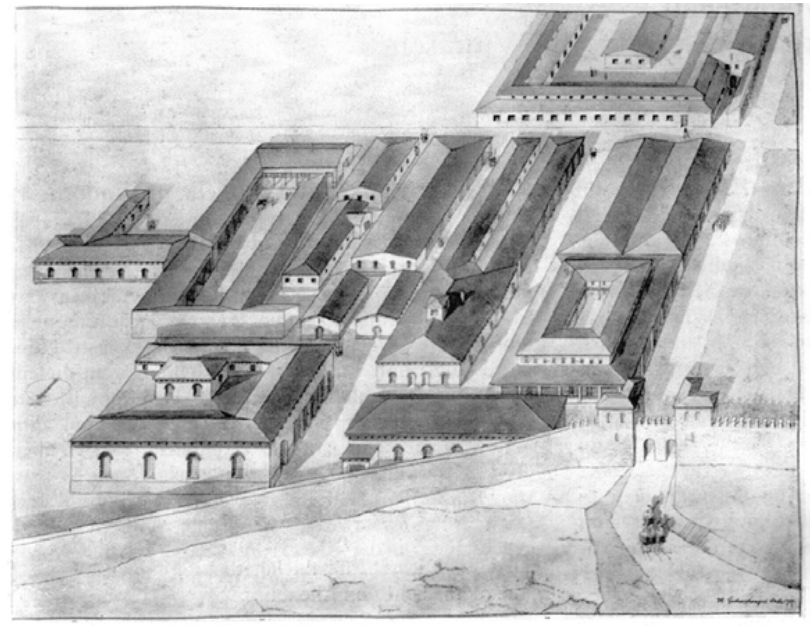

a)

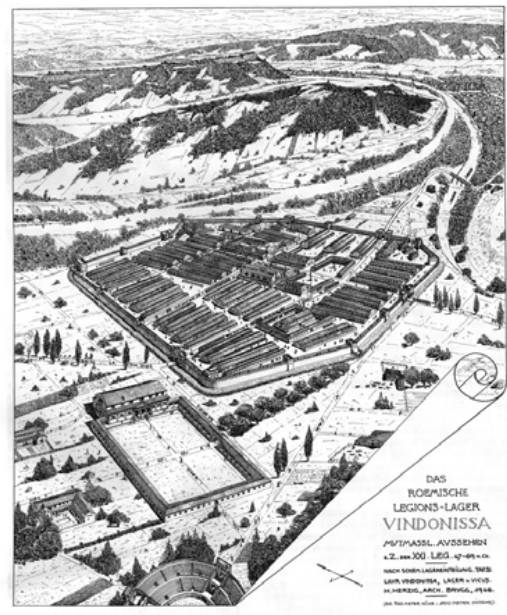

b)

Figure 1. Early visualizations of the Roman legion camp a) only known structures are depicted [Eichenberger 1939]; b) the first attempt at reconstructing the whole camp [Herzig 1945] 
It was not until 2001 that a new attempt at reconstructing the settlement was made by A. Haltinner (Fig. 2b). It left a lot of interpretation open to the viewer and did not go into detail where the underlying information was not clear enough. Quite contrary to that image, the next reconstruction from 2006 is very detailed and lively (Fig. 3). It attempts to capture the hustle and bustle that a citylike settlement with around 10,000 inhabitants must have had. Five years later, a 3D-model was printed and installed as a central piece of the permanent exhibition at the site's museum (Fig. 4). It has almost the same scientific basis as the previous image, but instead of focusing on the inhabitants of the camp, it depicts the buildings with a much higher level of detail.

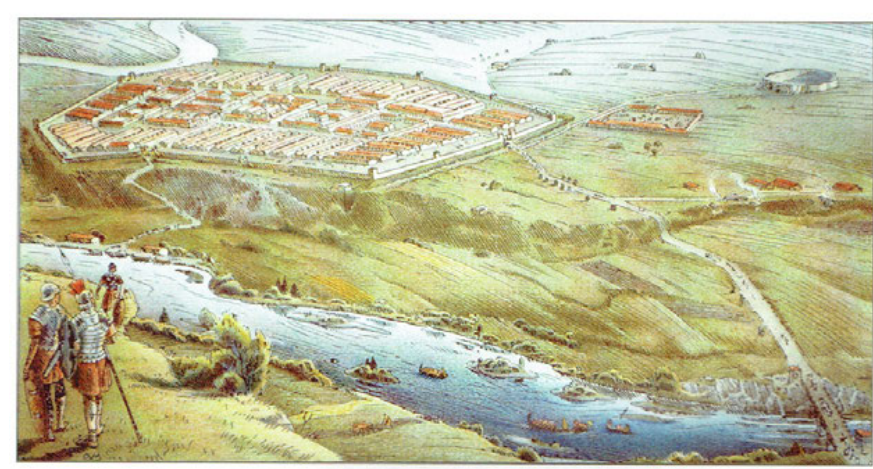

a)

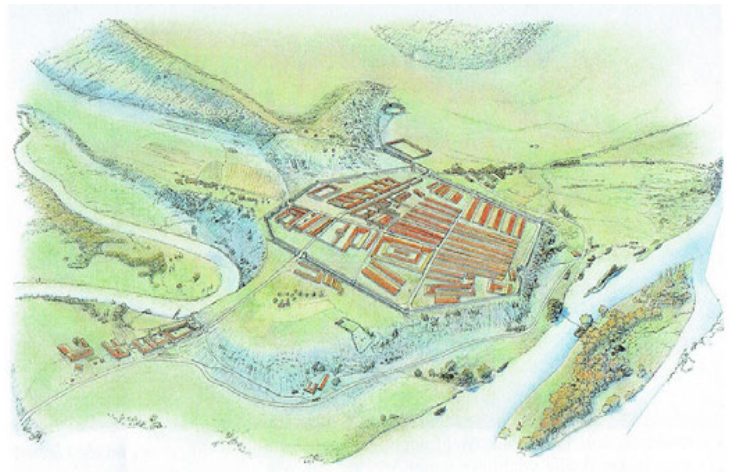

b)

Figure 2. More than fifty years apart but not so different: a) northern view by an unknown artist in the 1950s [Trumm 2016]; b) graphic approach at the start of the 21st century [Haltinner 2001]

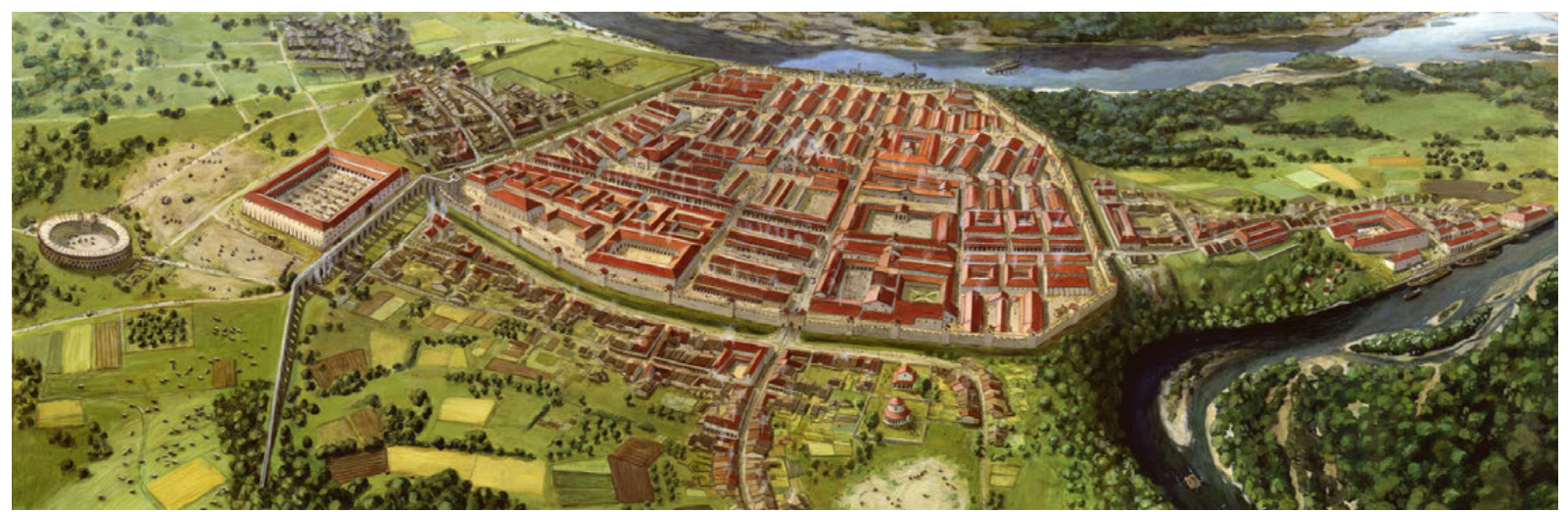

Figure 3. Showing a lively interpretation of the camp and its surroundings [Atelier Bunter Hund 2006] 


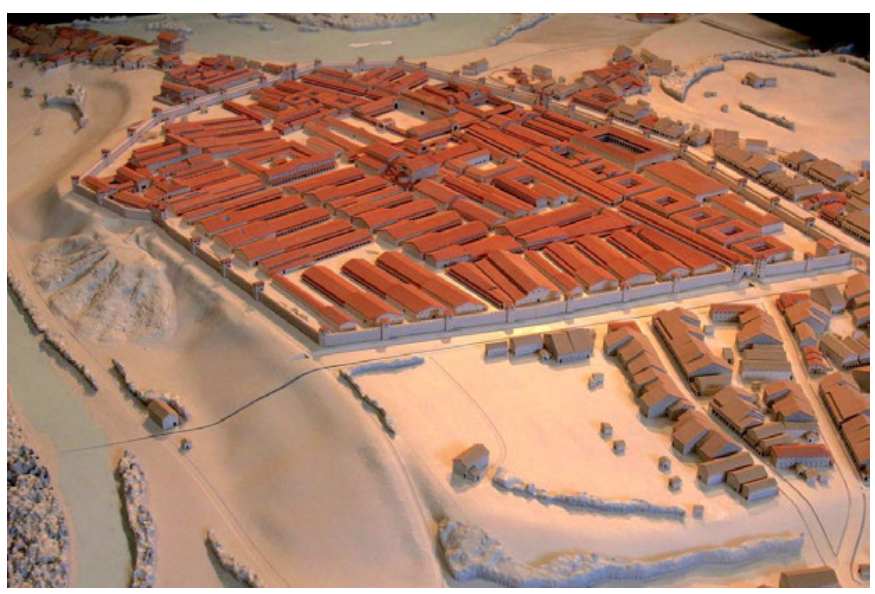

Figure 4. New media allowing for new forms of representations: 3D-printed model in the local museum [Flück 2011]

\section{CHALLENGES OF PRODUCING FOR MULTIPLE FORMATS}

The model mentioned above was available at the start of this project in a converted format, but it had originally been constructed for 3D printing. This meant that some details were missing and that, because of its polygon structure, it could not be included it in the texturing workflow. Instead of adapting the existing models to new needs, the decision was made to start again from scratch. In order to avoid remodeling for future uses, the model should be easily adaptable. The following section is an overview of present and future challenges and proposed solutions.

While some of these solutions are already common place in the workflow, others are more difficult to integrate or even mutually exclusive. Due to time and budget constraints, it was not possible to adhere to the proposed ideal solution. As a compromise, individual buildings were produced with a relatively low polygon count but with high quality textures. As the textures had to be painted for every building, these textures could be produced in a high resolution almost without any additional work. The number of template buildings was to be kept as low as possible to allow them to be replaced easily.

The archaeological service of the canton Aargau has a general plan which combines all excavation findings of the site. But the purpose of this plan was to give a general overview and visual summary, so it has been generated manually in Adobe Illustrator and does not include geodata. In 2017, work has started to generate a complete plan for CAD/GIS environments within a few years. This would facilitate the inclusion of georeferenced data in 3D models as well as the exchange between scientists and 3D artists.

In the project discussed in this paper however, it was not possible to georeference the archaeological findings because of the lack of a general plan. That and other limitations mean that the "living document" is still a long-term goal and not something that has already been achieved. Nevertheless, this document will shed a light on some considerations that should help working towards a real "living" version of Vindonissa. 
Table 1. Overview of the challenges faced in this project.

\begin{tabular}{|l|l|l|}
\hline \multicolumn{1}{|c|}{ Challenge } & \multicolumn{1}{c|}{ Goal } & \multicolumn{1}{c|}{ Proposed Solution } \\
\hline $\begin{array}{l}\text { Adapt the whole model for a bird's eye } \\
\text { use in AR/VR }\end{array}$ & $\begin{array}{l}\text { Model should be usable in a real-time } \\
\text { engine like Unity }\end{array}$ & $\begin{array}{l}\text { Keep the polygon count low and } \\
\text { textures easily scalable }\end{array}$ \\
\hline $\begin{array}{l}\text { Adapt buildings for close-up use in } \\
\text { AR/VR }\end{array}$ & Buildings need to have high quality & Produce high quality textures \\
\hline Adapt the landscape for use in AR/VR & $\begin{array}{l}\text { Produce 3D model of the landscape } \\
\text { with high detail in elevation }\end{array}$ & $\begin{array}{l}\text { Use a landscape tool in Unity to } \\
\text { create a detailed environment }\end{array}$ \\
\hline Landscape needed in still rendering & Produce a highly realistic image & $\begin{array}{l}\text { Camera-project Photoshop image } \\
\text { onto low poly surroundings }\end{array}$ \\
\hline $\begin{array}{l}\text { Adapt buildings according to new } \\
\text { scientific findings }\end{array}$ & $\begin{array}{l}\text { Individual models should be easy to } \\
\text { replace }\end{array}$ & $\begin{array}{l}\text { Keep the number of individual } \\
\text { models low and work with } \\
\text { instances }\end{array}$ \\
\hline Include archaeological findings & Georeference buildings & $\begin{array}{l}\text { Adapt proven buildings and include } \\
\text { the sources as metadata }\end{array}$ \\
\hline
\end{tabular}

\section{A WORKFLOW FOR LONG-TERM EFFECTIVENESS}

The basic information for the modeling (approximate number and size of windows, inclination of the roofs etc.) could be obtained from the model done in 2011. The appearance of the buildings inside the legion camp was therefore already set and only needed minor updates according to scientific findings. The discussion between the modeler and the expert was focused much more on the number and positioning of houses in the vici: Results of recent excavations indicate that the settlements around the legion camp were much smaller than previously thought.

Windows and doors were inserted into the basic models as Boolean objects using Cinema4D's MoGraph module. This allows one to change the number and positioning for each model while including a certain degree of randomness to make the model appear livelier. The roofs were modeled as separate objects so that they could be easily transferred between the template models. It would have been possible to use only as few as 16 polygons per roof, but they were instead cut into pieces of around 1 meter, as shown in Fig. 5.

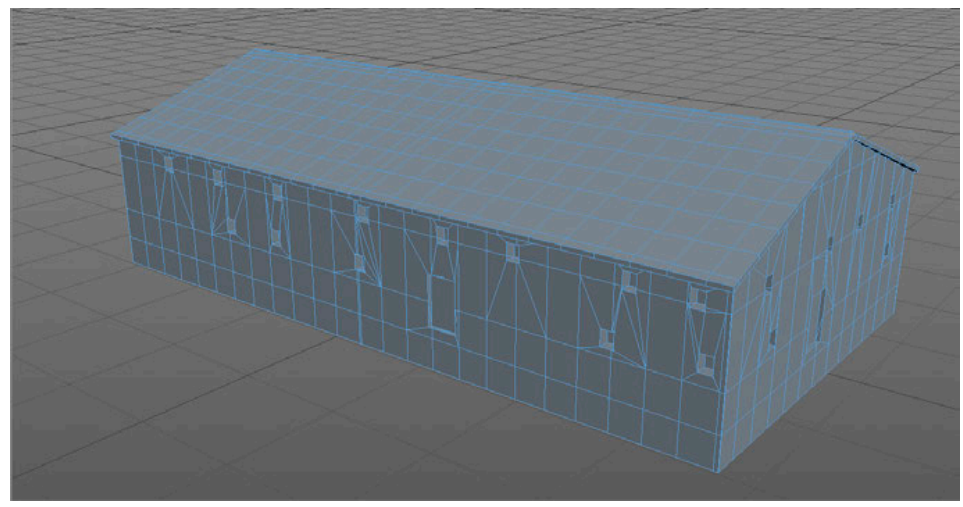

Figure 5. Buildings are cut into polygons of approximately even size for deformation. 
That allowed us to use a deformer which changes the location of each point by a few centimeters according to a black and white image, again with the goal of making the model look more life-like by avoiding totally straight forms.

All models are constructed so that they extend around one meter into the ground. This way their instances can be placed on uneven ground without risking that parts of the building appear to hover over the ground.

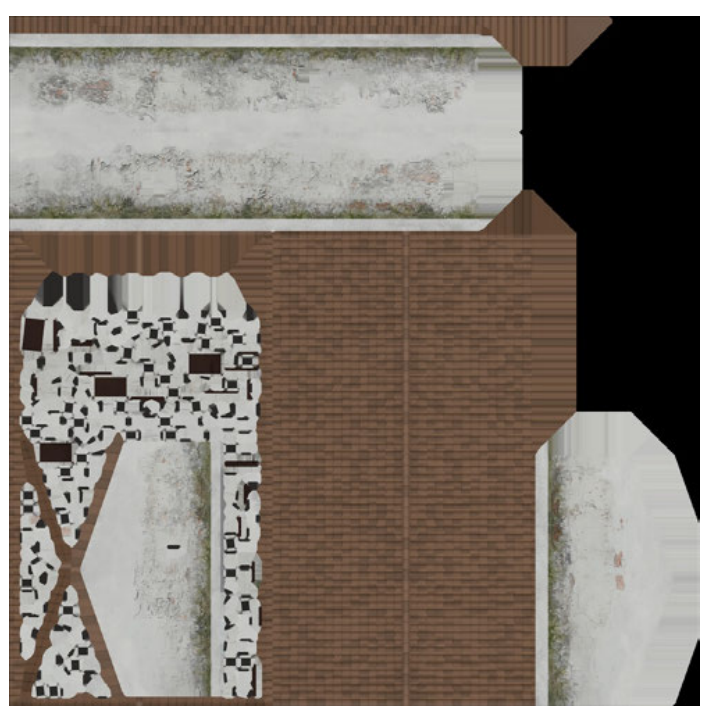

Figure 6. The painted texture as it looks after exporting from 3D-coat.

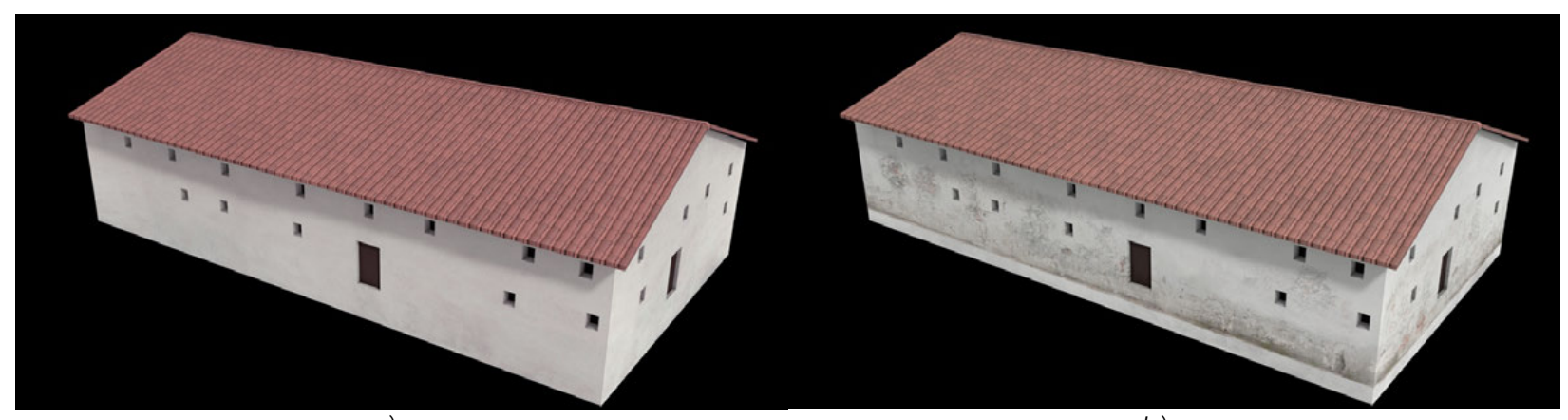

a)

b)

Figure 7. Variations can be obtained by turning layers on and off: a) recently built version; b) weathered and damaged version of the same building

The texturing workflow required working back and forth between applications. After a review of the suggested textures by the scientific expert, the models were exported from Cinema4D in OBJ format. From there, they were imported into 3D-Coat, which has very flexible UV-mesh and painting tools. The color information was applied in multiple layers, starting with the basic roof tiling and plaster 
before filling in a weathered and damaged look. These layers could be exported as separate images or combined in an editable Photoshop file like Fig. 6, including a normal map. Color correction and variation according to different ages of buildings can be applied easily as shown in Fig. 7. The textures were created in a resolution of 4096x4096 pixels, much higher than needed in the first set of renderings but again with the goal of using them in future close-ups.

To keep the modeling and texturing process as fast as possible, it was necessary to identify a group of base models that could be used multiple times within the legion camp. The 23 models in Fig. 8 were repeatedly used in around $95 \%$ of the buildings in the scene. The other $5 \%$ are special buildings such as the surrounding wall, the aqueduct, the amphitheater, etc. The base models could even be used for some special buildings like the baths in Fig. 9, with the reservation that for a closer look the model would have to be redone, as it lacks the detail of manually-made models. Each porticus in the scene uses the same original section of a porticus shown in Fig. 10 which is modeled with only 32 polygons and therefore saves much-needed computing power. Albeit these considerations, it is still necessary to convert the whole scene with a few manual steps before exporting it to real-time engines like Unity.

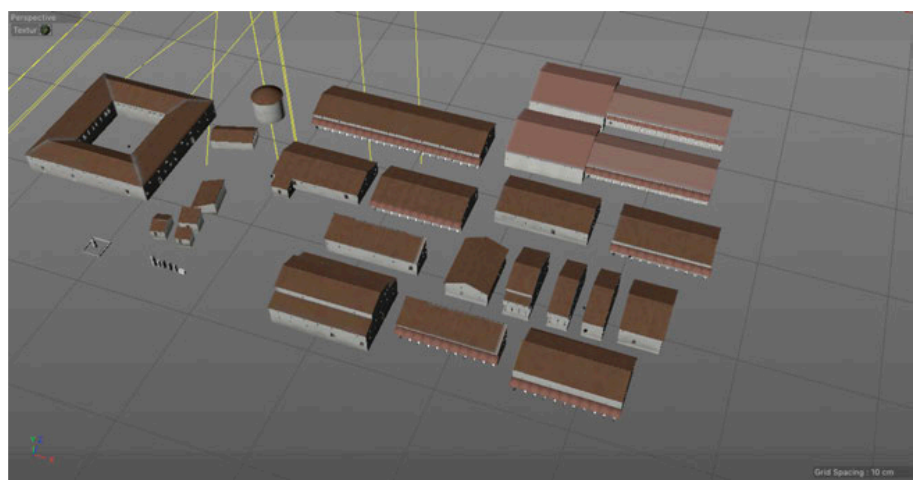

Figure 8. A repository of base models makes up most of the camp.

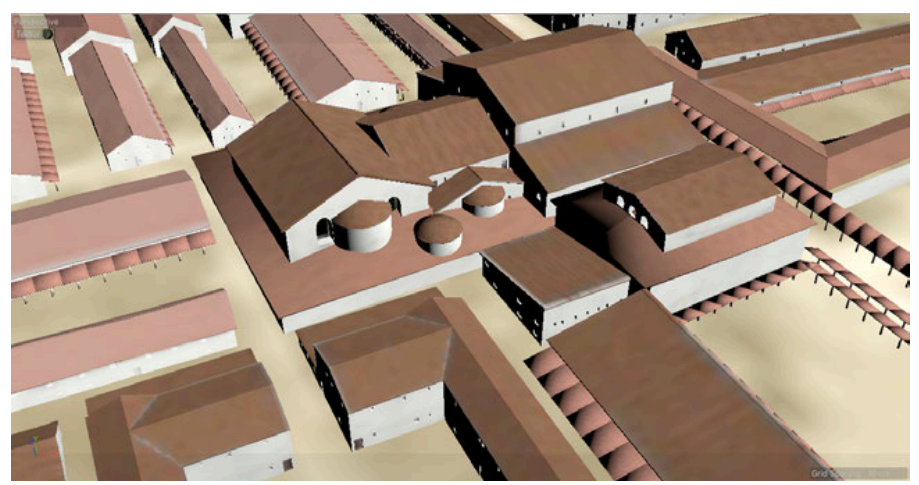

Figure 9. Even complex buildings can be composed of the base models as long as they are not viewed up close. 


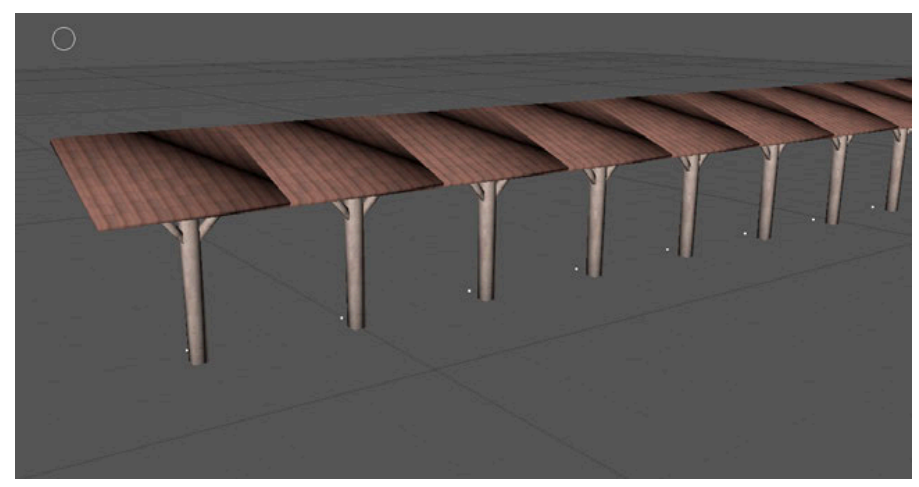

Figure 10. The original simple porticus is used throughout the whole scene.

The terrain is an area that required many compromises in this project owing to the different characteristics of working in the 3D modeling software Cinema4D and in the real-time engine Unity. In the modeling tool, the whole area is viewed from above and does not require a high polygon count or image resolution. In the real-time software on the other hand, the user will be standing on the ground and expect the terrain to simulate realistic bumps in elevation as well as high resolution textures. For the scope of this project, it was necessary to limit the resolution of the polygon mesh and the textures and work with a proven re-projection method shown in Fig. 11. A raw rendering of the terrain was imported to Photoshop and painted there according to details provided by the scientific expert. The resulting flat image was then camera-projected onto the terrain mesh which resulted in a highly variable look that allowed to change lighting settings dynamically.

Another obvious difference between pre-rendered images and real-time renderings is that, in the first, it is possible to apply color correction, fix mistakes and even apply atmospheric details such as smoke and clouds. For the application in a game engine all these effects need to be processed in realtime, which uses a lot of computing power and is therefore sparsely used in low-budget simulations.

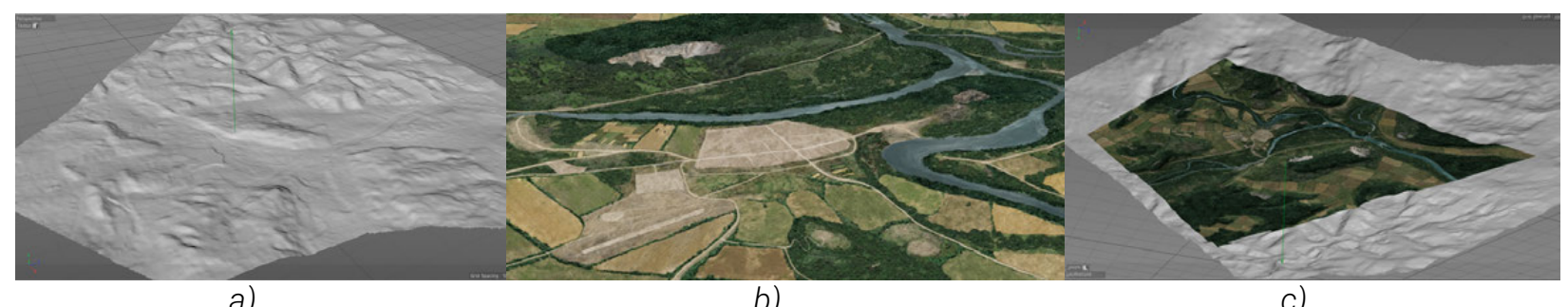

a)

b)

c)

Figure 11. The landscaping process: a) the visualized terrain data; b) painted texture in Photoshop without lighting or shadows; c) texture is reapplied onto the terrain through camera mapping 


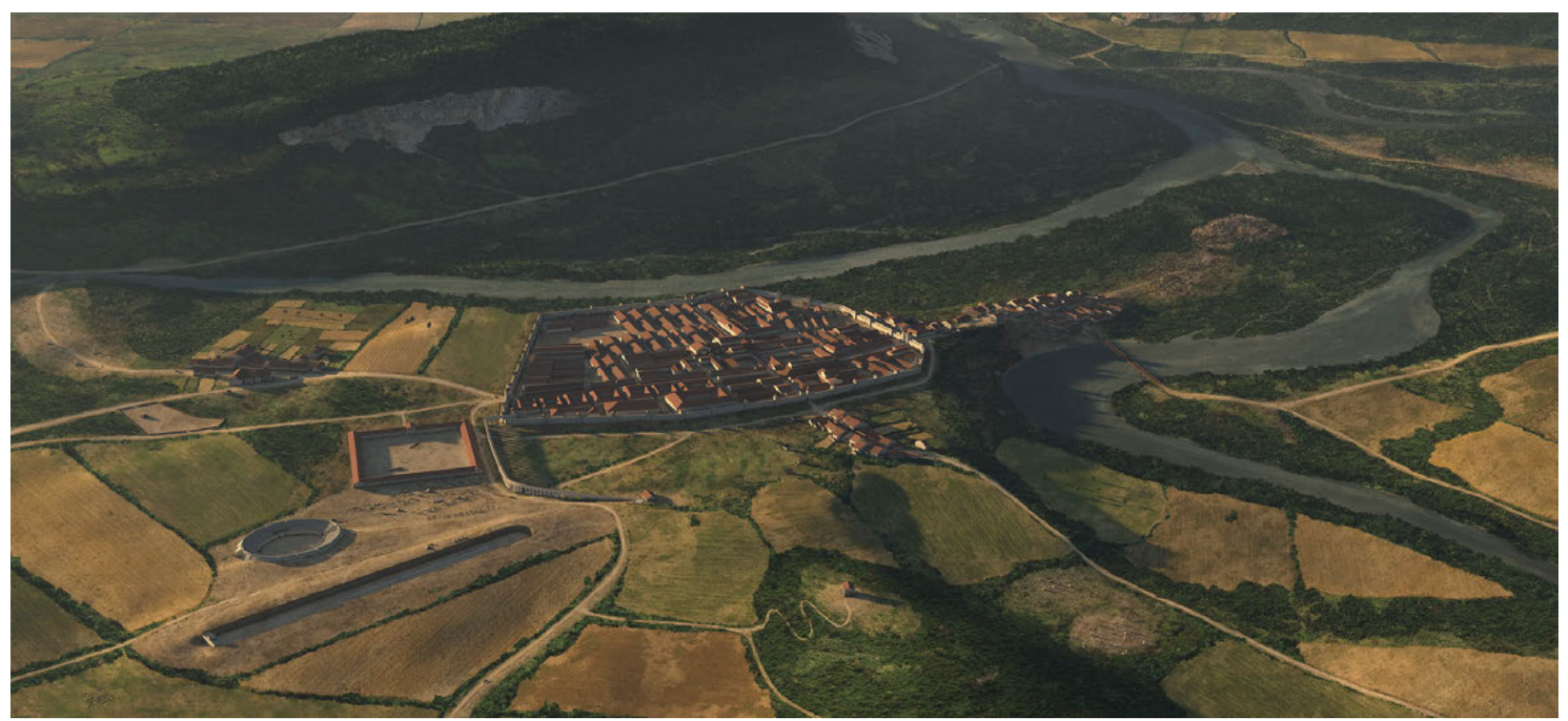

Figure 12. The raw rendering out of Cinema4D before applying atmospheric details in Photoshop.

\section{CHALLENGES AND LESSONS LEARNED}

Working efficiently for one primary output medium while keeping another in mind led to considerable challenges. The base models of houses, for example, had one initial size that had to be adapted for multiple uses in and around the legion camp. In extreme cases, the models changed from 0.5 up to 2 times of their original size. In the pre-rendered situation with a bird's eye view the resulting changes in texture and window size are not visible but if viewed from eye height these errors are noticeable and very distracting. More models would therefore have to be made if the whole camp should be made accessible in a close-up.

Some of the decisions taken at the start of the project were later considered obsolete and should not be repeated in future projects. The windows, for example, are just one polygon, which was then extruded to keep the polygon count low. Their appearance is not satisfactory in close-up and it would not have made a big difference in work or polygon count to include a bevel (curvature) to the window frames.

\section{CURRENT STATUS AND OUTLOOK}

The still renderings shown in Figs. 13, 14, and 15 were first published in the annual report of "Gesellschaft Pro Vindonissa" [Trumm 2016]. As there is currently no mandate or planned use for the real-time application, the execution of a proof of concept was pursued as an internal project at ikonaut. Further development of specific questions regarding movement and narrative interaction were posted as a student project at the University of Applied Sciences and Arts Northwestern Switzerland FHNW. A team of two students then created a framework shown in Fig. 16 that allows objects to be easily imported into an environment that has built-in functionality for a common form 
of teleportation locomotion as well as audio guide stations that are activated by the user. The next step will be to import the model of the whole legion camp into the real-time application and decide on one or multiple points of interest where a story can be told and where accessories and environmental effects will be added.

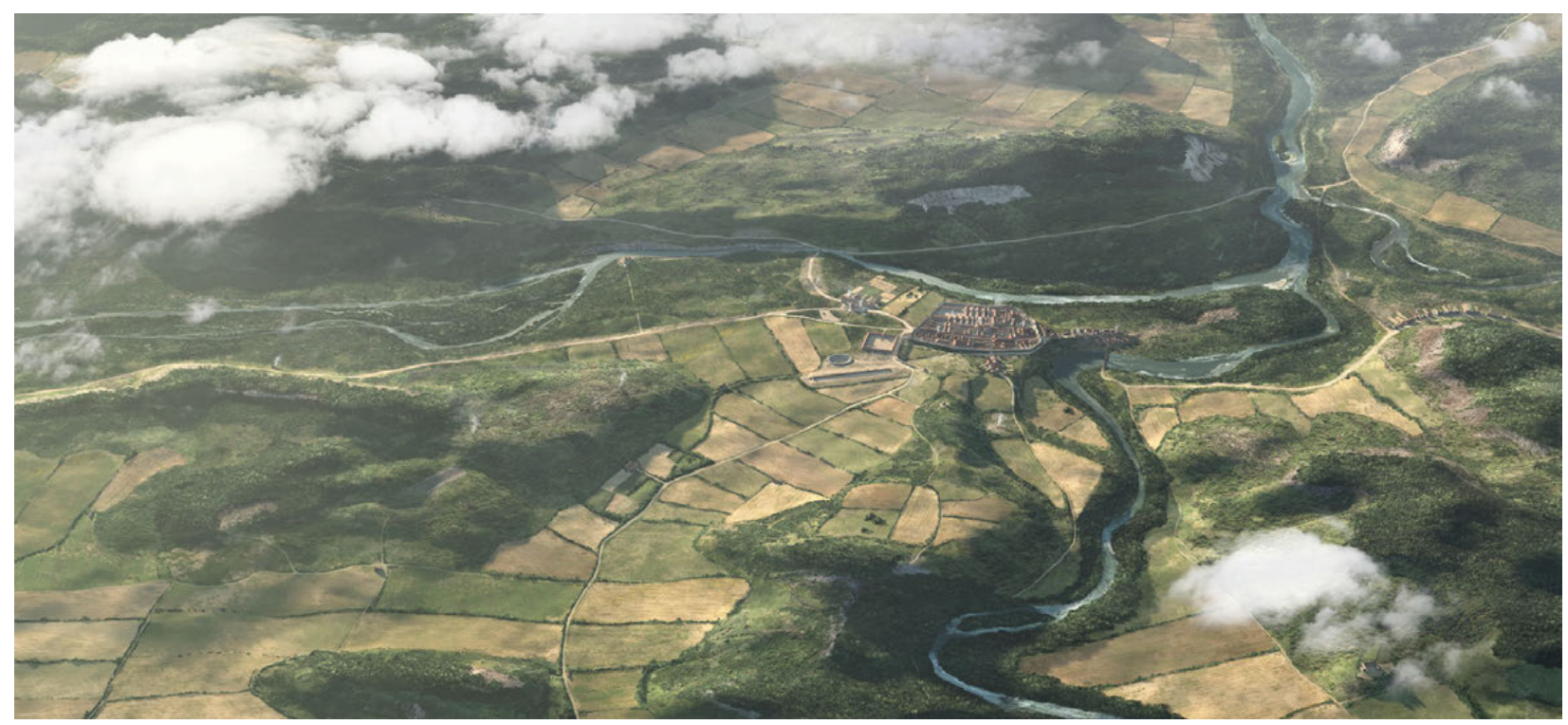

Figure 13. Final image, overview of the camp and its surrounding landscape in the 1st century AD

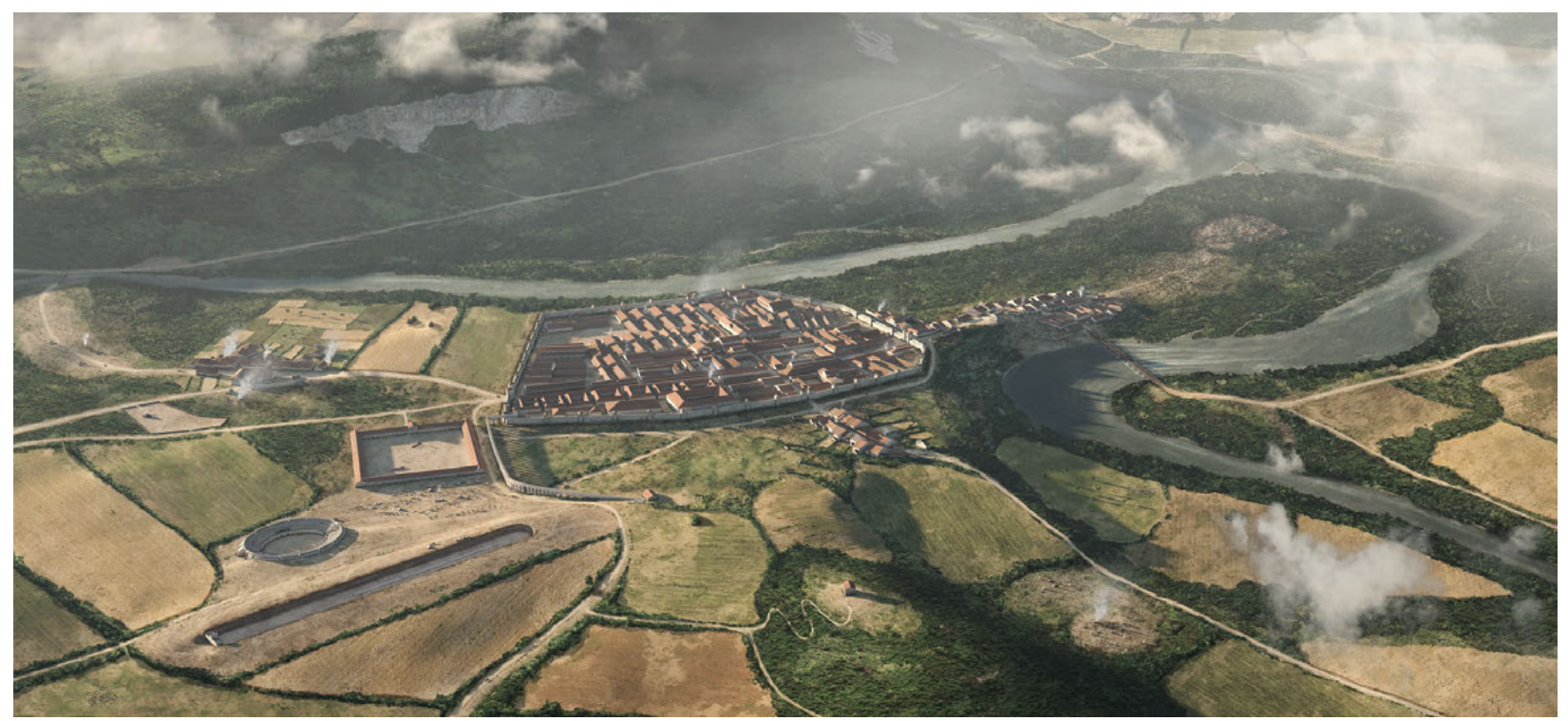

Figure 14. Final image, close-up of the camp in the 1st century AD 


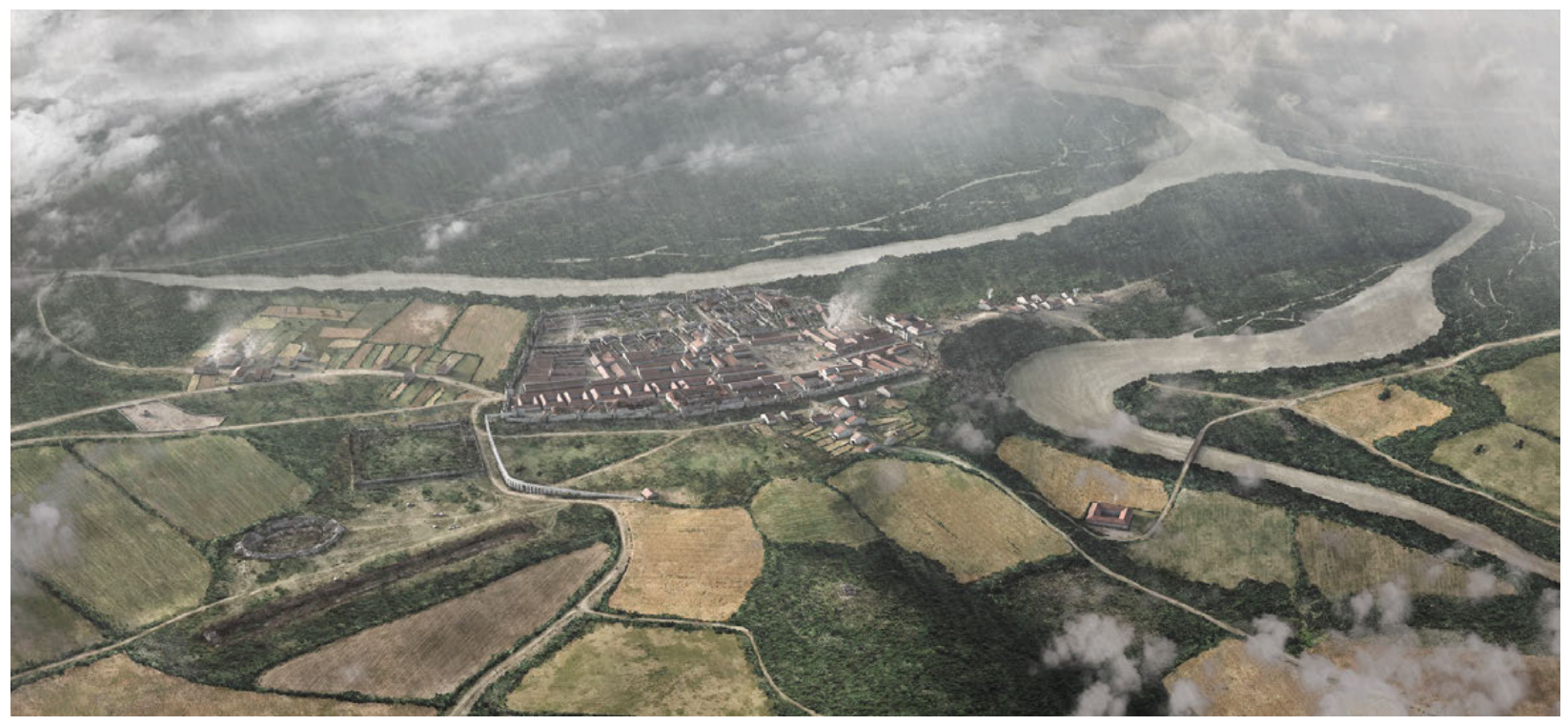

Figure 15. Final image, close-up of the settlement post military use in the 2 nd century $A D$

In the process of transferring models from Cinema4D to Unity it was noted that there is still a lot of manual labor involved for every object. Even when including the lessons learnt, the process is not satisfactory, and there is still a long way to go until it can be called a true "living document". In an idealized version of such a document, everyone involved in the production of knowledge in the project would enter additional data in the same file. All programs would draw their information from this file, from CAD to 3D and real-time applications. Such a solution would decrease the time needed for exchange and help to keep everyone aligned, from excavation personnel to archaeologists to 3Dartists and even the public.

Academic work has been done previously on different aspects of this bigger end-goal. Working group 5 of $\mathrm{COSCH}$ project exemplifies an international multidisciplinary approach to reach solutions for some of these issues [COSCH Action 2009]. While it will not be realistic for any one institution or company to solve the whole problem, it will make sense to achieve the long-term goal via small steps.

An example for such a small step is the plan to post another student project at FHNW outlining a solution for the automatization of the model exchange process. So-called "instances" from Cinema4D should be automatically transferred to "prefabs" in Unity4D. While their function is the same (have one original model cloned in order to safe processing power and allow for easy updatability) their practical application and the way the program handles them is different in both applications. Also, during the process the instances from Cinema4D will have to retain their name, which is given by the archaeologist's naming convention.

Another goal is to include documentation of background information and the way decisions were taken in the project in order to comply with principle 4 of the London Charter [London Charter Group 2009]. One of the solutions proposed at CHNT in earlier years, e.g. [Apollonio 2016] or [Hauck and Kuroczynski 2015] could be applied. For a private company, it would be preferable to have a 
minimalistic documentation standard that could be expanded upon later. As the documentation process is (not yet) a part of the project outline and therefore not paid, it would only be feasible to include documentation if the workflow needed is not too time consuming.

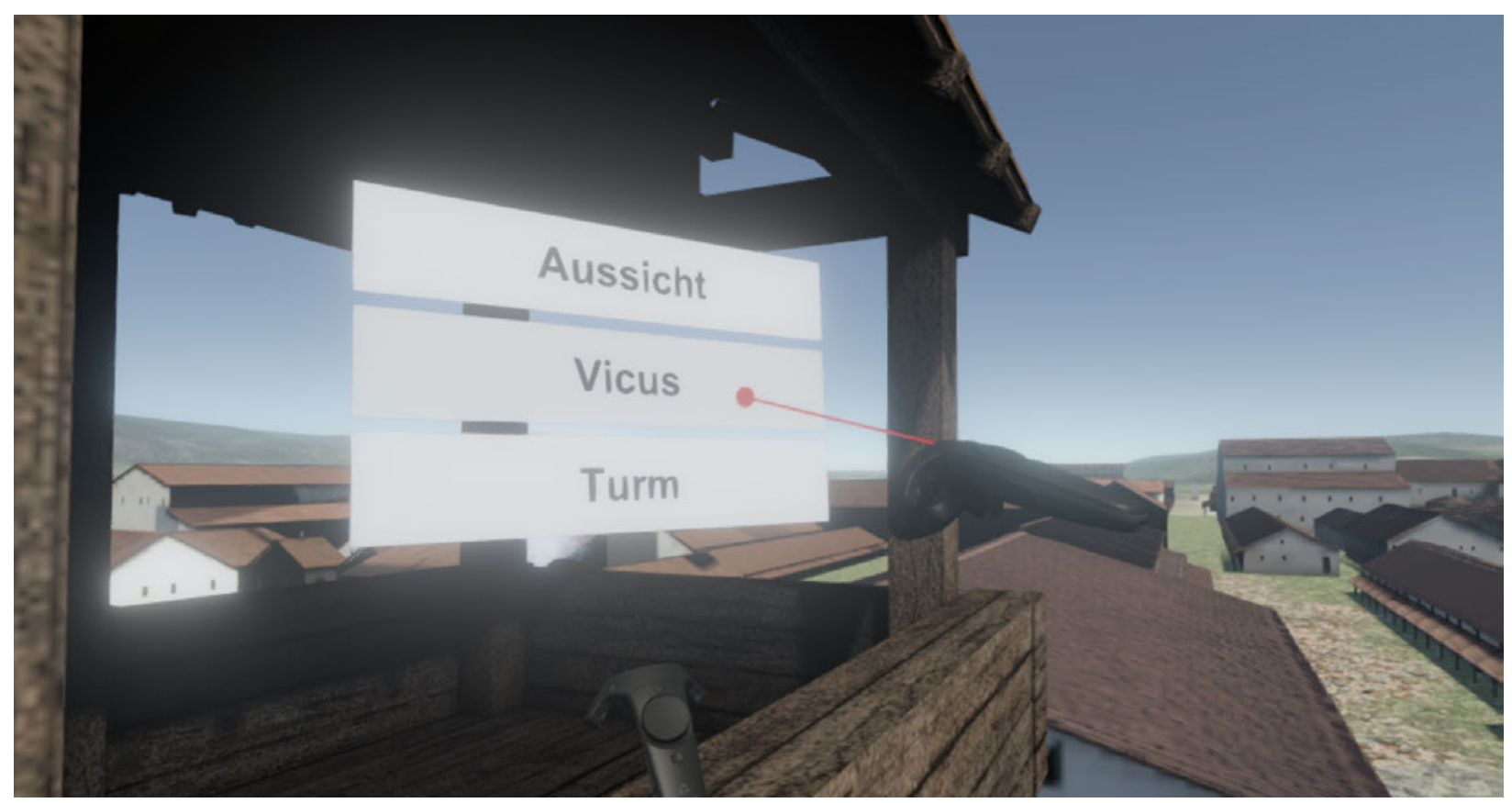

Figure 16. First look at the Virtual Reality implementation in Unity. A navigation menu with available locations is displayed. The user teleports to new locations using hand controllers.

\section{CONCLUSION}

This paper presented a method for the 3D-modeling of a Roman legion camp, planning for output in multiple formats from pre-rendered to real-time rendering. Some of the ideas put forward could be applied universally when working on a large-scale 3D model of a settlement where a lot of buildings can be classified into types thanks to their repetitive nature.

Some challenges inherent to the goal of producing for pre-rendered and real-time renderings at the same time were mentioned. Most notably, these challenges include the level of detail for modeling the buildings and the terrain. In pre-rendered scenarios from a bird's eye view, the buildings can be modelled with few polygons and low-resolution textures while the terrain can be painted in an external software. Including 3D vegetation is computationally expensive and not necessary. On the contrary, in real-time renderings from an eye-level perspective, house models need more detail in modeling and textures. The terrain must include 3D vegetation, if a realistic look is desired. Combining these elements is only possible when extra time and budget are available, though small preventive measures, some of them outlined in this paper, can help to keep later development time down. 
1:408 J. Christen

\section{REFERENCES}

Atelier Bunter Hund. 2006. In Beat Gutshauser, Andrea John \& Felix Boller. Leben im Aargau. Buchs: Lehrmittelverlag des Kantons Aargau, $36 f$.

COSCH Action. 2017. Working Group 3: Algorithms and procedures. Retrieved May 20, 2017: http://cosch.info/wg3.

Fabrizio Apollonio. 2016. Classification schemes and model validation of 3D digital reconstruction process. In International Conference on Cultural Heritage and New Technologies, Vienna, 2015 - Proceedings. Retrieved January 30, 2017 from CHNT: http://www.chnt.at/wpcontent/uploads/eBook_CHNT20_Apollonio_2015.pdf.

Hans Herzig. 1946/47. Versuch einer Rekonstruktion der Tore, Türme und Umwallung von Vindonissa. In Gesellschaft Pro Vindonissa, ed. Jubiläumsbericht 1946/47. Brugg: Vindonissamuseum, 68.

Jürgen Trumm \& ikonaut. 2016. Vindonissa aus der Vogelschau - Neue und alte Blicke auf das römische Windisch. In Gesellschaft Pro Vindonissa, ed. Jahresbericht 2015. Brugg: VindonissaMuseum, 11.

Jürgen Trumm. 2015. Vindonissa. In Historisches Lexikon der Schweiz (HLS). Retrieved July 30, 2017 from HLS: http://www.hls-dhs-dss.ch/textes/d/D12287.php.

Karin Meier-Riva. 2001. Unter der Erde. Vom Leben und Sterben in Vindonissa, 7.

London Charter Group. 2009. The London Charter for the Computer-Based visualization of cultural heritage. Retrieved January 30, 2017:

http://www.londoncharter.org/fileadmin/templates/main/docs/london_charter_2_1_en.pdf.

Matthias Flück. 2011. The printed legionary camp of Vindonissa - The development of a new digital and physical model of Vindonissa. In International Conference on Cultural Heritage and New Technologies, Vienna, 2010. Retrieved January 30, 2017 from CHNT: http://www.chnt.at/wpcontent/uploads/eBook_WS15_Part3_Sessions1.pdf.

Oliver Hauck, Piotr Kuroczynski. 2015. Cultural Heritage Markup Language - How to Record and Preserve 3D Assets of Digital Reconstruction. In International Conference on Cultural Heritage and New Technologies, Vienna, 2014. Retrieved January 30, 2017 from CHNT: http://www.chnt.at/wp-content/uploads/eBook_CHNT20_Hauck_Kuroczynski_2015.pdf.

Walter Eichenberger. 1938/39. Frontispiece. In Gesellschaft Pro Vindonissa, ed. Jahresbericht 1938/39. Brugg: Buchdruckerei Effingerhof AG, Frontispiece.

Received January 2017; revised July 2017; accepted August 2017.

Studies in Digital Heritage, Vol. 1, No. 2, Publication date: December 2017 